\title{
Design as a Condition for Prosperity in Czech Businesses - A Comparative Study
}

\section{- Kramolis Jan}

\begin{abstract}
The purpose of the paper is to comprehensively review the sources of design management, business prosperity and competitiveness. The study shows the current situation in Czech businesses. Furthermore, this paper also attempts to analyze and identify the awareness of companies concerning the relation to design as a condition for business prosperity. The primary aim of the research is to investigate design as a condition of prosperity in Czech businesses.

A comprehensive review of the extant literature and journals identified several sources of design approach and various definitions of business prosperity. The research consists of two main parts. Firstly, a method of smart internet questionnaires designed by the author was used. After that, the data were analyzed using mosaic plot and elementary statistics calculations, and seeking mutual dependence, followed by a comparative method. Finally, the findings were processed by comparative study that aims to compare the years 2012 and 2014. The results of the research offer interesting findings. This paper identifies several interesting aspects regarding design within Czech companies, including the mindset of management (the insight gap of Czech businesses regarding design in their business).
\end{abstract}

Keywords: design management, competitiveness, prosperity, design, economic welfare, marketing JEL Classification: M21, O31, M31

\section{INTRODUCTION}

Competitiveness is a key factor of Czech businesses in today's growing market. Market in the Czech Republic is almost fully saturated; the way to success is not the lowest price only. Along with the growth of living standards and increasing incomes, consumers are changing their preferences. There are many successful companies that innovate; they offer attractive products and do effective marketing. Their products are not only visually aesthetic using attractive packaging. Moreover, these products are related to corporate visual marketing communications. A relationship between business prosperity and design seems to be therefore a crucial challenge. These ambitious companies, which are aware of this challenge, know that it is important to invest money in design and to work with long-term marketing. Indeed, this fact confirms that the design management is a possible way to achieve dream success on the market.

\section{THEORETICAL BACKGROUND}

Design management is defined by Hollins (2002) as the organization of the process for developing new products and services. According to Kathryn Best (2006), in the area of design manage- 
ment a wide variety of perspectives exist that reflect the rich array of individuals, professions and context involved. Fundamental issues of design management are identified by Bruce and Bessant (2002): How do particular perspectives fit into the design process and what they can bring; How can design professionals support these different contributions; What tools/techniques are available to help make this contribution; How can the effectiveness of the design process be measured; How can the process be improved. According to Design Management Institute in Boston (2014), the definition Design management encompasses the ongoing processes, business decisions, and strategies that enable innovation and create effectively-designed products, services, communications, environments, and brands that enhance our quality of life and provide organizational success. On a deeper level, design management seeks to link design, innovation, technology, management and customers to provide competitive advantage across the triple bottom line: economic, social/cultural, and environmental factors. It is the art and science of empowering design to enhance collaboration and synergy between 'design' and 'business' to improve design effectiveness. The scope of design management ranges from the tactical management of corporate design functions and design agencies, including design operations, staff, methods and processes - to the strategic advocacy of design across the organization as a key differentiator and driver of organizational success. It includes the use of design thinking-or using design processes to solve general business problems. There is a strong link between marketing and the design management which mentioned Gorb (1988) and also Melewar, Dennis and Kent (2014), and Adir and Pascu (2012) present in their paper the importance of a logo as a graphic element to support a corporate identity. They described the basic idea: The logo design is a creative work which allows a company to be seen through a symbol as a visual and graphic message. Design thinking as a mechanism for brand ambidexterity is explained by Beverland (2015). The author highlights two key implications for brand managers focused on recognizing the need for design thinking and organizing in such a way as to encourage the achievement of brand ambidexterity. Although it may be tempting to suggest that brand managers become more like designers or adopt a design thinking approach, he cautions against such a view. Moreover many of the organizations studied had systems and structures ensuring that designers and brand managers interacted regularly and had strong working relationships.

Design offers four powers or directions through which to create value in management, and these four directions can be seen as a system with the vision in the center according to Mozota (2002), (2003), and (2006). The design value model and its application through the Balanced Score Card toolkit provide a common language for designers and managers and this can help the design profession effect a change from project-based to knowledge-based. Oakley (1990) deals with a specific field of management. He presents the differences between managers and designers The differences between the managers and designers are mainly in the area of personality traits, habits of thinking and working, and education background. The design management according to Best (2006) illustrates three main phases: 


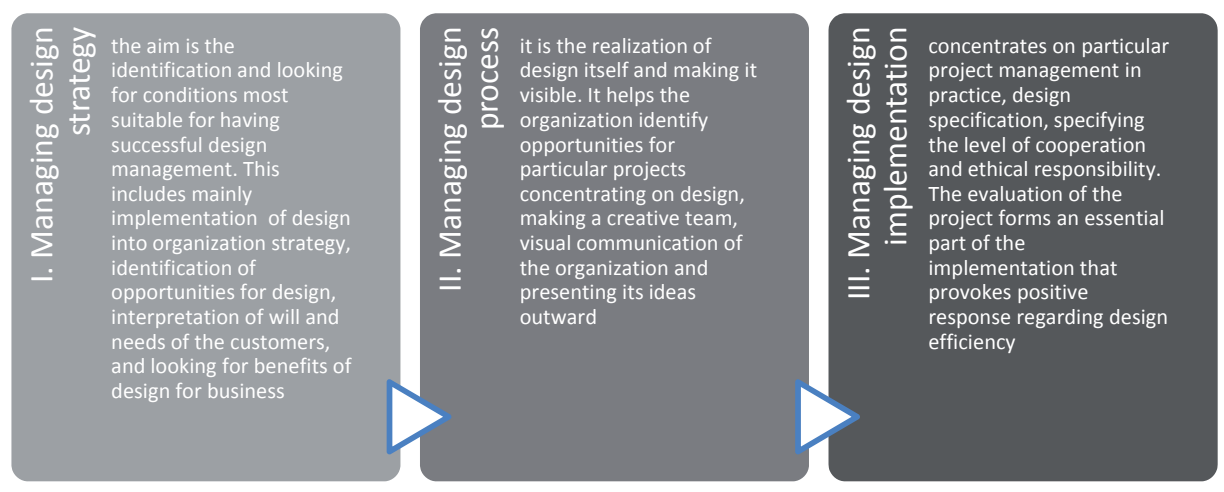

Fig. 1 - Three main phases of the Design management (Best, 2006)

A design-driven innovation is introduced by Verganti (2009). He also defines three phases related to innovation management by means of design:

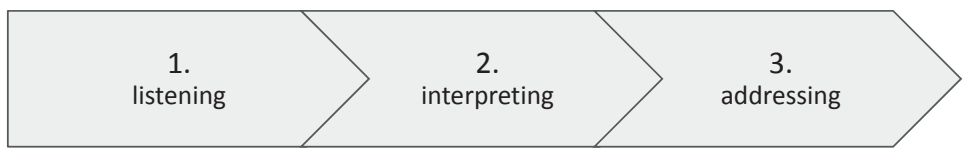

Fig. 2 - Three phases related to innovation management by means of design (Verganti, 2009)

The first phase 'listening' consists of listening to the key groups, i.e., interpreters. Interpreters are people who predict future development of customers' needs by means of their own research. The aim of 'listening' is to find the key groups of interpreters and predict benefits of their thoughts for business. The main key groups according to Verganti (2009) are artists, cultural organizations, sociologists, anthropologists, marketers, retail and delivery firms, people, designers, firms in other industries, developers of pioneering projects, technology suppliers and research and educational institutions. The second phase is 'interpreting'. Its purpose within the company is to create such conditions that would propose a motion. The organization communicates with the interpreters and integrates their ideas with technology and possibilities of the company. The third phase is 'addressing'. This means making such conditions to be able to innovate, and to discuss the rationality and attractions of the change.

Bruce and Bessant (2002) also state the major benefits of the design management:

- Increase profit by increasing sales or by decreasing manufacturing costs.

- Increase market share.

- Gain a competitive advantage.

- Revamp mature and failing products.

- Provide a strategy for growth.

- Design is a way of launching a new product of service. 
The UK Design Council focuses on the contribution made by design and presents mail responses (Bruce and Bessant, 2002): 91\% of respondents felt it improved the image of their company, $84 \%$ felt it helped increase profit, $80 \%$ felt it helped them expand into new markets, $70 \%$ felt it reduced costs.

Mazota (2003) deals with the topic of Design as a competitive edge. The author measures the impact of design on product, classifying the reasons for launching new products and the tacit knowledge of design. This research can be useful for professional design managers because it isolates variables that are pertinent to explain how design transforms management processes and which process it changes. According to Bruce \& Cooper \& Vazquez (1999), small companies have a range of business needs for design, but have varying levels of awareness and competency to manage design effectively. Two different types of companies could be discerned from the study: 'confident' and 'apprehensive' design users. The former companies had had experience with design, typically in previous work experience and the latter had little awareness of design. For the inexperienced design companies, various factors were identified that assisted the effective design outcome: the relative simplicity of the project, possession of strong briefing skills acquired in a different discipline, sourcing skills, such as personal recommendation form a trusted intermediary, and evaluation skills obtained through an intermediary or acquired in a different discipline. Bruce and Cooper (1999) also identify the ways in which small manufacturing and service companies use professional design skills and their approaches to managing product, engineering and graphic design in relation to effective design for small businesses. Herrmann (2000) mentioned that the design of product quality has come to be seen not merely as the task of a single functional unit, but as a central challenge for any company. This altered perspective was brought about by the realization that superior products are available in many branches of industry, in terms of both price/cost and quality. Indeed Gmuer (2015) states facts in his study: design may contribute to the understanding of the interaction between psychological factors (processing fluency) and sensory processes during the post-consumption evaluation. Moreover, the gained knowledge of design features may be useful for marketing specialists and label designers to optimize their decision-making processes and improve their marketing strategies. In addition, Gemser and Leenders (2001) argued that, it is very likely that the impact of design on company performance will vary depending on the skills and talents of the people involved in the design process. Consequently, Taraba (2010) mentioned that the holistic competence of an individual should be one of the important factors for creating a successful team. The research study by Roy and Porter (1993) confirms the finding that graphic design projects are significantly more likely to be profitable than projects involving product design expertise or projects involving engineering or engineering plus industrial design. However, their results explain that, once the projects are put into production, the likelihood of product or engineering projects being profitable is almost as great as that for graphics projects. Indeed, the difference in risk is not statistically significant.

\section{Design as a competitive advantage}

There are a few studies concerning design and business prosperity (in particular packaging design, which is only one part of design management fields). Overall, there is a general lack of case studies and papers on design management. One of the preferably useful is Packaging design 
study: creating competitive advantage with product packaging (Rundh, 2009). This study looks into how packaging and packaging design can contribute to competitive advantage for marketing a consumer product and also emphasizes and underscores the importance of different internal and external influences that participating actors have to consider in the design process. Quite similar is a study by Barnes, Southee and Henson (2003) which deals with the impact of affective design of product packaging topic. There is also another study seeking the importance of packaging design for own-label food brands in the UK. (Wells, Farley, Armstrong, 2007): "By identifying the segments that purchase premium own-label and the factors that influence their choice, retailers can then develop a packaging design that enhances brand awareness and creates positive associations within the consumers' consciousness. Overall, the analysis demonstrated the growing importance that is placed on packaging as a tool for differentiation from competitor products and for further developing the retailer's own-label brand. The analysis of findings would clearly indicate that there is a strong association regarding the influence of packaging on the purchase decision. The importance of packaging design 685 with over $73 \%$ of interviewed consumers stating that they rely on packaging to aid their decision-making process at the point of purchase."

\section{Business prosperity}

There is one reference to design and prosperity by Karpissova (2009), who states selected internal competitiveness aspects in her working paper (linked to business prosperity). One of many factors influencing prosperity is named 'brand, visual design and innovation politics'.

According to the Answers Corporation (2015), economic prosperity is a relative term. On the whole, it means that the economy is doing well and most people have sufficient income for essentials and perhaps a little extra. It means that businesses are hiring and jobs are relatively easy to get. It does not mean that everyone has a job or that everyone is well off. Another mention refers to the Prosperity Index by the Legatum Institute (2015), a constructed global index that measures national prosperity based on both wealth and wellbeing. This Index includes national prosperity as a matter of fundamental importance, factors such as democratic governance, entrepreneurial opportunity, and social cohesion. This covers $96 \%$ of the world's population and $99 \%$ of global GDP. Furthermore, a quite different index is the Genuine Progress Indicator (Smith et al., 2013) created in 1995 by a socially responsible think tank called Redefining Progress. It was developed as an alternative to the traditional GDP measure of a nation's economic and social health. Read on to find out what GDP fails to reveal about a country's economic prosperity and how the genuine progress indicator works to make up this gap. Lloyd and Ramsay (2014) argue that economic prosperity has a strong link with improving social welfare through market-induced efficiency, in the public interest. As a result, there is an idea that 'prosperity' is not just a macroeconomic measure but should be a social construct.

Another macroeconomic opinion on the prosperity is offered by Cowling (2006) in his paper 'Prosperity, Depression and Modern Capitalism', which could be directly linked to welfare and meta-preferences. 


\section{PROBLEM FORMULATION}

Three main research problems have been formulated. All of them are identified with design and business prosperity describing the evolution of the current situation in comparison with 2012. The first one is the issue of verifying design results based on economic indicators (quantitative). The second one is the issue of the possible importance of design in business success. And the last one is searching for any connection between design and business prosperity (eventually the issue of detecting a direct relation). Using a comparative study (Vesterstrøm, Thomsen, 2004), evolutionary algorithms on numerical benchmark problems of design management could be explained.

\section{RESEARCH METHODS}

The research was carried out from January to March 2014; a method of smart internet questionnaires (Google Spreadsheet) was used. It was designed by the author of the paper based on the experience from his previous research. The questionnaire form contains 16 questions. The responses were divided into several categories with common features. In total, 166 entries collected from 305 addressed respondents took part in the research. The results obtained were subjects to a statistical study.

The obtained data were subsequently compared with the previously unpublished research from 2012. This original research was conducted by our partner (Richtr, 2012) from the Dynamo design company. The research was conducted in the same manner as the research from 2014 (via email, included original research questions, which were slightly updated for new research; questionnaires were addressed to the same respondents). This file includes 144 valid entries. Possible dependencies and the common features of both files were searched using XLstatistics software.

The resulting mosaic plot gives a graphical estimation of the joint distribution of its attributes. Two-dimensional mosaic plots (Hoffmann, 2000) were created for each research question, these figures were modeled in the software Statgraphics in order to seek dependence. Conventional mosaic plot is to graphically represent contingency tables by tiles whose size is proportional to the cell count (Huh, 2004). The tool demonstrates the effectiveness of visual inference using a real data set. These tests were performed at the significance level of $\alpha=0.05$.

Finally, the descriptive comparisons were used, aimed at describing and perhaps also explaining the invariance of the objects.

Three primary Research Questions (RQ) linked to the formulated topics were established after data adjustment. These Research Questions were statistically analyzed.

- $\mathrm{R}_{1}$ : Do you verify design results in your business based on economic indicators?

- $\mathrm{R}_{2}$ : How important is design for your business success?

- $\mathrm{R}_{3}$ : Is there a link between design and prosperity of your business? 


\section{Data adjustment}

It was necessary to adjust the gathered entries of closed question into two categories (Yes; No). Adjusting approach explanation shows that: Possible answers with high certainty no have been assigned to a variable NO. All other positive answers were assigned to variable YES. The specific assignment is illustrated in the table below (Tab. 1). Finally, in 2014 research, the option 'yes, absolutely' was removed from the questionnaire, because based on previous experience, this option is almost identical to answer 'yes, always' and unnecessarily directs respondents to check average.

Tab. 1 - The adjustment of gathered data (source: own)

\begin{tabular}{|l|c|c|}
\hline \multicolumn{3}{|c|}{ Year $2012(n=144)$} \\
\cline { 1 - 1 } $\begin{array}{l}\text { Questionnaire } \\
\text { response }\end{array}$ & $\begin{array}{c}\text { Assigned } \\
\text { variable }\end{array}$ & $\begin{array}{c}\text { Interpre- } \\
\text { tation }\end{array}$ \\
\cline { 1 - 1 } No, never & NO & Disagree \\
\hline Yes, once & YES & Agree \\
\cline { 1 - 1 } Yes, sometimes & & \\
\cline { 1 - 1 } Yes, almost always & & \\
\cline { 1 - 1 } Yes, absolutely & &
\end{tabular}

\begin{tabular}{|l|c|c|}
\hline \multicolumn{3}{|c|}{ Year $2014(n=166)$} \\
\hline $\begin{array}{l}\text { Questionnaire } \\
\text { response }\end{array}$ & $\begin{array}{c}\text { Assigned } \\
\text { variable }\end{array}$ & $\begin{array}{c}\text { Interpre- } \\
\text { tation }\end{array}$ \\
\cline { 1 - 1 } No, never & NO & Disagree \\
\cline { 1 - 1 } Yes, once & YES & Agree \\
\cline { 1 - 1 } Yes, often & & \\
\cline { 1 - 1 } Yes, always & &
\end{tabular}

\section{PROBLEM SOLUTION}

The first research question labeled $\mathrm{R}_{1}$ is: Do you verify design results based on economic indicators?

The previous research from two years ago showed that, according to respondents, design had a measurable effect on economic indicators; almost two thirds of surveyed respondents reported and measured the effects of design in their economic statements. However, the actual research indicates that this value dropped down rapidly. That means that only half of managers evaluated the effects of design in economic statements. Numerical benchmark: the fact that design was never measured in companies was claimed by only $37.4 \%$ of managers in 2012 , but the situation deteriorated up to a full half of respondents in 2014.

The constructed mosaic plot (Fig. 3) graphically shows the layout of results visualizing the polarity of values. The plot below will be used for searching for statistical dependencies. 


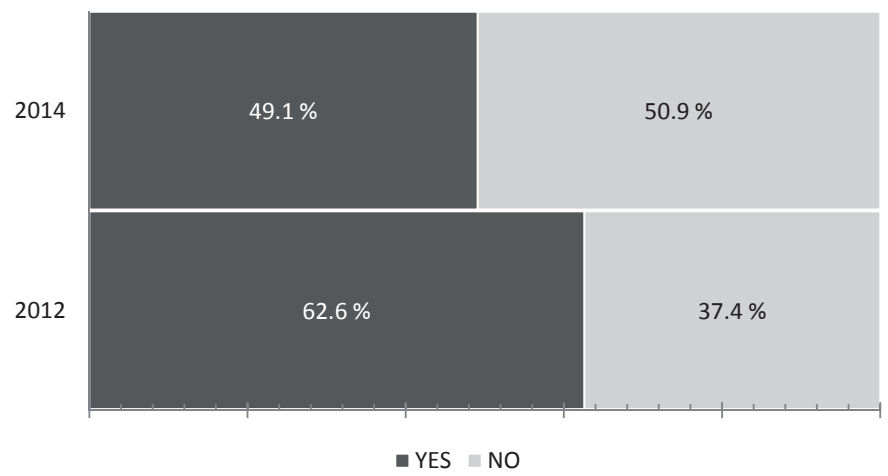

Fig. 3 - The Mosaic plot of $\mathrm{R}_{1}$ (source: own)

Visually the mosaic plot demonstrates that color distribution is almost the same in both rows, which indicates the independence of categorical variables. The exact conclusion could be set by the p-value $\chi^{2}$ - test below. It was performed as the Analysis of Data for Two Categorical Variables in accordance with the $\mathrm{R}_{1}$ in XLstatistics (Excel Workbooks for Statistical Analysis). The results are shown in the following screenshot (Fig. 4).

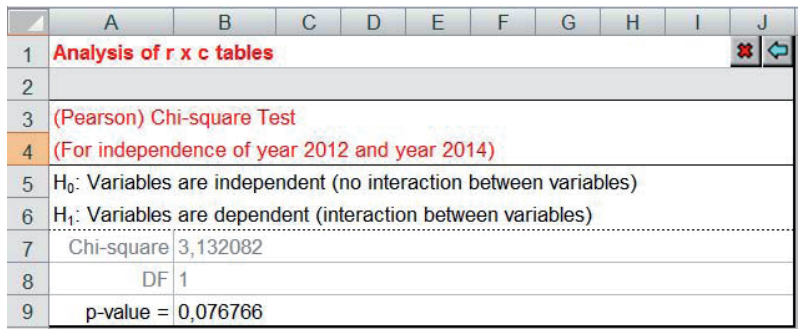

Fig. 4 - The screenshot for $\mathrm{R}_{1}$ Chi-square Test (XLstatistics; own calculation)

The Chi-square value was calculated 0.076 and is apparently higher than 0.05 value, so it can be claimed that the tested values are independent.

In question of "verifying design results based on economic indicators" was found independent between years 2012 and 2014.

The following second research question labeled $\mathrm{R}_{2}$ is: How important is design in your business success?

In 2012, the vast majority of companies considered design as important for business success. In contrast, the current research indicates a rise of skepticism; only $78 \%$ of managers believe in the importance of design in connection with business success. A negative attitude in the original study was nearly one percent, but a sharp rise in skepticism revealed in year 2014 with almost $22 \%$ of negative attitudes related to the importance of design in business success. 
The constructed mosaic plot (Fig. 5) graphically shows the layout of results visualizing the polarity of values. The plot below will be used for searching for statistical dependencies.

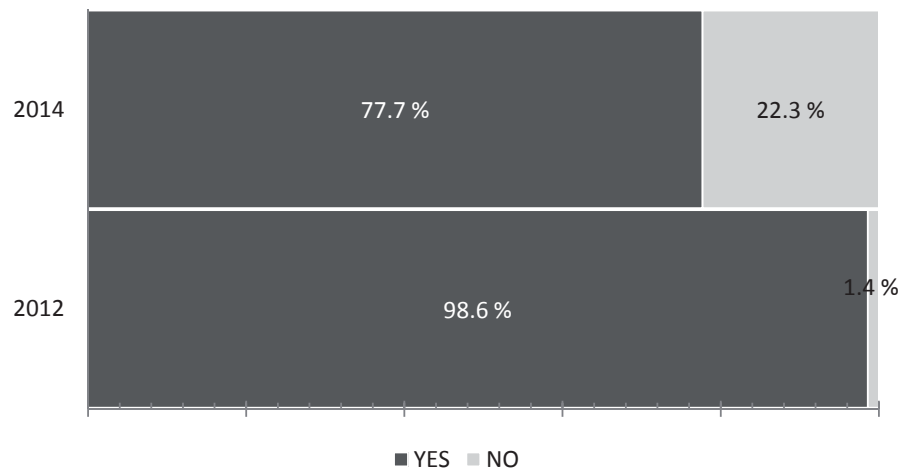

Fig. 5 - The Mosaic plot of $\mathrm{R}_{2}$ (source: own)

Visually the mosaic chart demonstrates that color distribution is almost the same in both rows, which undoubtedly indicates the dependence of categorical variables. The exact conclusion could be set by the p-value $\chi^{2}$ - test below. The Analysis of Data for Two Categorical Variables in accordance with the $\mathrm{R}_{2}$ in XLStatistics (Excel Workbooks for Statistical Analysis) was performed. The results are shown in the following screenshot (Fig. 6).

\begin{tabular}{l|l|}
\hline 1 & Analysis of $\mathrm{r} x \mathrm{c}$ tables \\
\hline 2 & \\
\hline 3 & (Pearson) Chi-square Test \\
\hline 4 & (For independence of year 2012 and year 2014) \\
\hline 5 & $\mathrm{H}_{0}$ : Variables are independent (no interaction between variables) \\
\hline 6 & $\mathrm{H}_{1}$ : Variables are dependent (interaction between variables) \\
\hline 7 & Chi-square 30,62683 \\
\hline 8 & DF 1 \\
\hline 9 & p-value $=3,13 \mathrm{E}-08$ \\
\hline
\end{tabular}

Fig. 6 - The screenshot for $\mathrm{R}_{2}$ Chi-square Test (XLstatistics; own calculation)

The Chi-square value was calculated 0.0000000313 and is apparently at zero level. This value is lower than alpha 0.05 , so it can be claimed that the tested values are strongly dependent.

"The importance of design in your business success" is highly dependent between years 2012 and 2014.

Finally, there is the third research question labeled $\mathrm{R}_{3}$ : Is there a relation between design and the prosperity of your business?

This issue is more general in nature, i.e., it examines the awareness of the existence of any relation to design and the development of a firm. Both surveys have shown very strong evidence of the existence of this relationship. Companies in the Czech Republic are almost 100\% certain that there is in general a link between design and business prosperity. The fact that there is no correlation in the current research is considered as negligible by $2.1 \%$. Insignificant but still only 
a slight increase in skepticism regarding design and business prosperity can be found, as well as in the previously examined issue $\mathrm{R}_{2}$.

The constructed mosaic plot (Fig. 7) graphically shows the layout of results visualizing the polarity of values. The plot below will be used for searching for statistical dependencies.

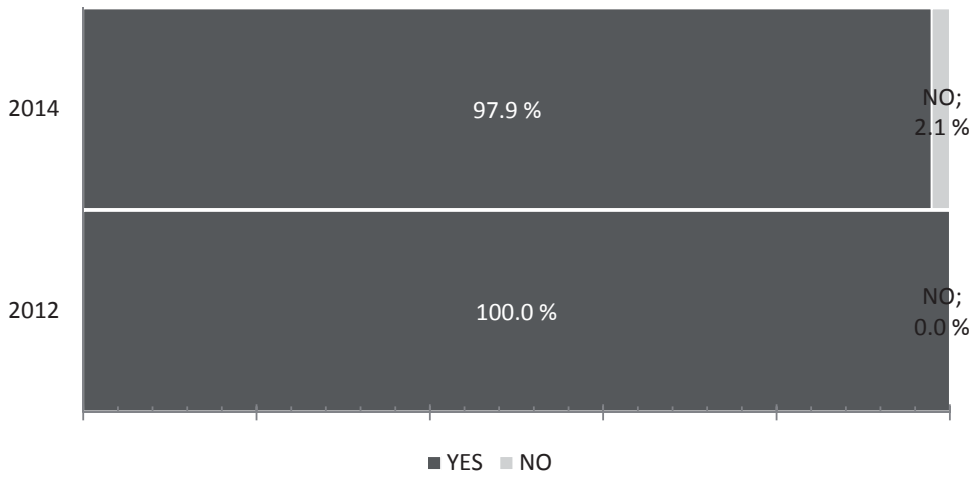

Fig. 7 - The Mosaic plot of $\mathrm{R}_{3}$ (source: own)

Visually the mosaic chart demonstrates that color distribution is almost the same in both rows, which indicates the independence of categorical variables. The exact conclusion could be set by the p-value $\chi 2$ - test below. The Analysis of Data for Two Categorical Variables was performed in accordance with the R3 in XLStatistics (Excel Workbooks for Statistical Analysis). The results are shown in the following screenshot (Fig. 8).

\begin{tabular}{|l|l|}
\hline 1 & Analysis of $\mathrm{r} x \mathrm{c}$ tables \\
\hline 2 & \\
\hline 3 & (Pearson) Chi-square Test \\
\hline 4 & (For independence of year 2012 and year 2014) \\
\hline 5 & $\mathrm{H}_{0}$ : Variables are independent (no interaction between variables) \\
\hline 6 & $\mathrm{H}_{1}$ : Variables are dependent (interaction between variables) \\
\hline 7 & Chi-square 2,65369 \\
\hline 8 & DF 1 \\
\hline 9 & p-value $=0,10331$ \\
\hline
\end{tabular}

Fig. 8 - The screenshot for $\mathrm{R}_{3}$ Chi-square Test (XLstatistics; own calculation)

The Chi-square value was calculated 0.103 and is apparently higher than 0.05 value, so it can be claimed that the tested values are independent.

The relation between "design" and "the prosperity of business" is independent in years 2012 and 2014.

\section{The statistical and comparative conclusion}

The table (Tab. 2) below illustrates aggregated XLstatistics outputs among research questions. The columns show the main numbers of observed file (The Pearson Chi-Square Tests, Confidence Intervals), and research questions are displayed in the rows according to the research aim. 
Tab. 2 - The Pearson Chi-Square Tests (source: own)

\begin{tabular}{|l|c|c|c|c|}
\hline \multicolumn{4}{|c|}{ Pearson Chi-Square Tests } & $\begin{array}{c}\text { Confidence } \\
\text { Intervals }\end{array}$ \\
\hline & Chi-square & DF & P-value & Margin of error \\
\hline $\mathrm{R}_{1}$ & 3.13 & 1 & 0.076 & 0.14996 \\
\hline $\mathrm{R}_{2}$ & 30.63 & 1 & $0.00313^{-5}$ & 0.06655 \\
\hline $\mathrm{R}_{3}$ & 2.65 & 1 & 0.103 & 0.02105 \\
\hline
\end{tabular}

It is obvious that strong dependence was found in the research question $\mathrm{R}_{2}$ only.

The highest Chi-square which shows the statistical significance of the file has been measured at the $R_{2}$ - the value of 30.63 which indicates high reliability. In $R_{1}$ and $R_{3}$ were measured significantly lower values of 3.13 and 2.65 (log-likelihood) which indicates low relevance (effect size). $\mathrm{DF}$ (degrees of freedom) is for all research questions at the same level. The last indicator, P-value, concerning $R_{1}$ and $R_{3}$ is higher than $\alpha 0.05$. Only the research question $R_{2}$ has a significantly lower p-value.

In a comparative study, two events were examined as can be viewed in the table below, where a column represents a variation between years 2012 and 2014. The rows stand for specified research questions $\mathrm{R}_{1}, \mathrm{R}_{2}$ and $\mathrm{R}_{3}$.

Tab. 3 - A brief quantitative comparative study (source: own)

\begin{tabular}{|c|c|c|}
\hline \multicolumn{3}{|c|}{$\begin{array}{l}2012 \text { and } 2014 \text { comparative table of answers } \\
\text { according to research questions. }\end{array}$} \\
\hline & & Variation (\%) \\
\hline \multirow{2}{*}{$\mathrm{R}_{1}$} & YES & $-21.56 \%$ \\
\hline & $\mathrm{NO}$ & $+36.10 \%$ \\
\hline \multirow{2}{*}{$\mathrm{R}_{2}$} & YES & $-21.44 \%$ \\
\hline & NO & $+1428.5 \%$ \\
\hline \multirow{2}{*}{$\mathrm{R}_{3}$} & YES & $-2.86 \%$ \\
\hline & $\mathrm{NO}$ & $+42.86 \%$ \\
\hline
\end{tabular}

The crucial changes between 2012 and 2014 can be observed in the research question $\mathrm{R}_{2}$ : 'How important is design in your business success?' This variation had a gigantic increase of $1428.5 \%$. On the other hand, nearly identical numbers in both surveys can be found in $\mathrm{R}_{3}$ : 'Is there a relation between design and the prosperity of your business?' where is a slight shift of $2.86 \%$.

\section{DISCUSSION}

The main discussed issue in this paper is the relation between design and business prosperity. The investigation was aimed at finding out whether the managers are aware of the above relation. 
What is important to mention is that the research did not investigate how strong the relation is. This question was asked to gain general awareness of a possible link between design and business prosperity.

For this reason, the extra aim of research was linked to Bruce and Bessant (2002) theory (they found that " $91 \%$ felt it improved the image of their company") to prove or disprove their facts. Indeed, this situation is very similar in the Czech Republic, where the vast majority of respondents $(100 \%$ in $2012 ; 98 \%$ in 2014) confirmed the awareness of this relation.

Bruce and Bessant (2002) also stated the major benefits of design management, we can be strongly confident that almost the same situation can be seen in Czech businesses nowadays.

Graphical representation of the research outcomes draws the figure below (Fig. 9), which has been compiled: Design in business - opinion polarity gap, which compares the two poles of awareness among managers in the Czech Republic between years 2012 and 2014.
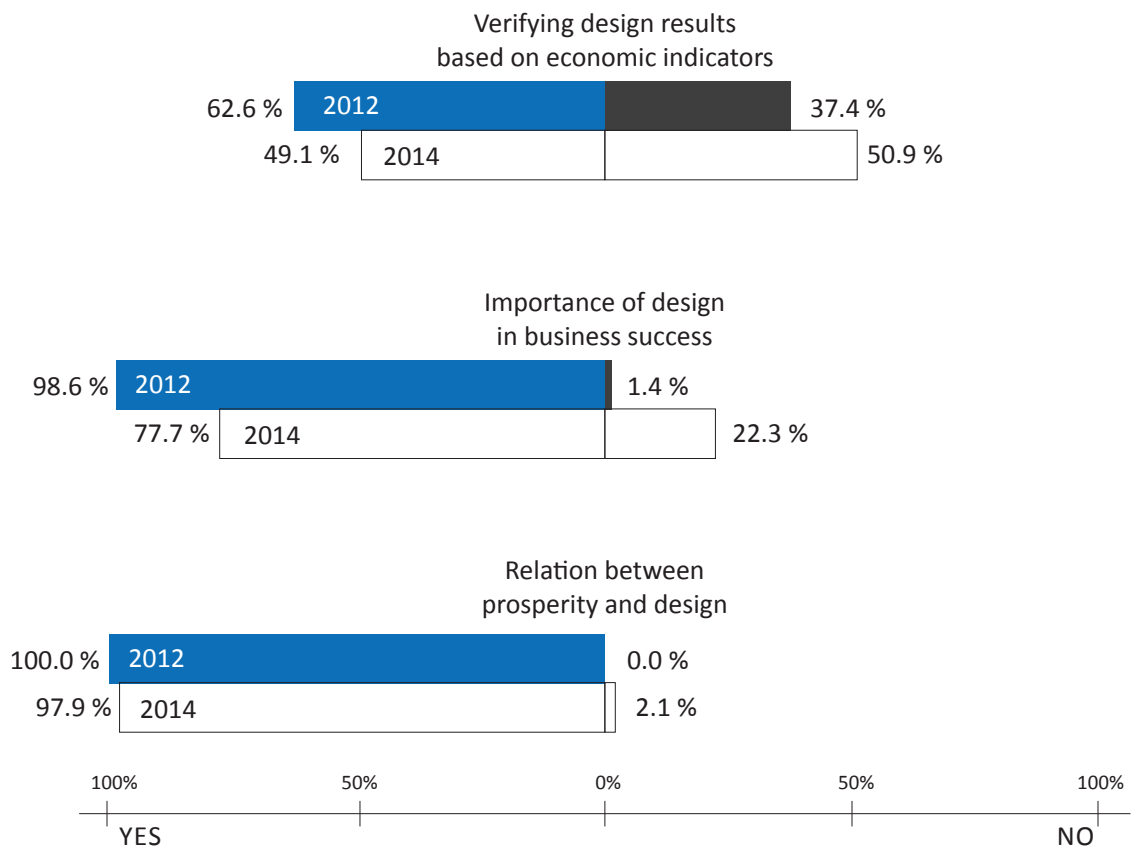

Fig. 9 - The insight gap of Czech businesses regarding design in their business (source: own)

Main findings according to figure above could be briefly summarized:

- Is design important for business prosperity? This issue can be quite clearly explained, because almost $99 \%$ of managers agreed with this statement (in 2012). Only $1 \%$ considered this issue unimportant.

- Managers are well aware of what design is and of the fact that it can be an added value in a competitive environment. Again, there is a significant increase in skepticism in 2014. 
- For example 99\% (design importance in business success) has strongly decreased up to $78 \%$. Also, there is a strong increase in skepticism from $1 \%$ up to $22 \%$. As a result, there is an indication of the significant shift in this issue. It could be explained as a response to the lingering macroeconomic crisis in the Czech Republic.

Indeed, while comparing this research outcome to Bruce and Bessant (2002) some similarities could be found. Bruce and Bessant claimed that: "91\% felt it improved the image of their company" and these facts apparently show similarities with main outputs from the research.

Nevertheless, despite the fact that the questions in research were slightly differently formulated, the general findings from the research are very similar, especially in 2012.

\section{CONCLUSION}

Corporate managers know that they can measure the effects of design in terms of economic reports. This finding is showed in the original research from year 2012 by almost two-thirds of respondents. The question is why the remaining one-third of respondents do not measure the economic performance of design. A probable explanation could be that there is a lack of time to evaluate these data, or that the managers do not consider it important in their strategy.

The main outcome from the 2014 research indicates that there is skepticism among the respondents.

Barely one half measures design effectiveness using the economic indicators. This fact means that every second company is not interested in measuring economic results in this field. The possible reason is attributable to a lingering macroeconomic crisis in the Czech Republic. While the annual GDP growth fluctuates around zero, companies are likely to work hard to make a profit and try to cut costs while surviving on the market. Therefore all other activities (such as measuring the economic effects of design) are considered to be minor.

\section{Limitations}

A weakness of the presented research could likely be that the respondents could made some mistakes while completing the questionnaire. Especially in the question of understanding the term 'verifying results based on economic indicators' and 'business success'. It is possible that some respondents understood prosperity in connection with positive economic values, rather than as an overall view of the company excluding financial indicators.

\section{References}

1. Ad, G., Adr, V., \& Pascu, N. E. (2012). Logo design and the corporate identity. ProcediaSocial and Behavioral Sciences, 51, 650-654. doi:10.1016/j.sbspro.2012.08.218

2. Barnes, C., Southee, C., \& Henson, B. (2003). The impact of affective design of product packaging upon consumer purchase decisions. In Proceedings of the 2003 international conference on Designing pleasurable products and interfaces (pp. 134-135).

3. Best, K. (2006). Design Management: managing design strategy, process and implementation. AVA publishing. 
4. Beverland, M. B., Wilner, S. J., \& Micheli, P. (2015). Reconciling the tension between consistency and relevance: design thinking as a mechanism for brand ambidexterity. Journal of the Academy of Marketing Science, 1-21.

5. Bruce, M., \& Bessant, J. R. (2002). Design in business: Strategic innovation through design. Pearson education.

6. Bruce, M., Cooper, R., \& Vazquez, D. (1999). Effective design management for small businesses. Design studies, 20(3), 297-315.

7. Cowling, K. (2006). Prosperity, depression and modern capitalism. Kyklos, 59(3), 369-381.

8. DESIGN MANAGEMENT INSTITUTE. (2014). What is Design Management? Design Management Institute. Retrieved June 14, 2015, from http://www.dmi.org/?What_is_ Design_Manag.

9. Gmuer, A., Siegrist, M., \& Dohle, S. (2015). Does wine label processing fluency influence wine hedonics? Food Quality and Preference, 44, 12-16.

10. Gorb, P. (1988). Corporate identity design; Its contribution to effective management. European Management Journal, 6(3), 205-208.

11. Gemser, G., \& Leenders, M. A. (2001). How integrating industrial design in the product development process impacts on company performance. Journal of Product Innovation Management, 18(1), 28-38.

12. Herrmann, A., Huber, F., \& Braunstein, C. (2000). Market-driven product and service design: Bridging the gap between customer needs, quality management, and customer satisfaction. International Journal of production economics, 66(1), 77-96. doi:10.1016/s09255273(99)00114-0

13. Hofmann, H., Siebes, A. P., \& Wilhelm, A. F. (2000). Visualizing association rules with interactive mosaic plots. In Proceedings of the sixth ACM SIGKDD international conference on Knowledge discovery and data mining (pp. 227-235). ACM.

14. Hollins, B. (2002). Design management education: The UK experience. Design Management Journal (Former Series), 13(3), 25-29. doi:10.1111/j.1948-7169.2002.tb00315.x

15. Huh, M. Y. (2004). Line Mosaic Plot: Algorithm and Implementation. In COMPSTAT 2004_Proceedings in Computational Statistics, 277-285. doi:10.1007/978-3-7908-2656-2_22.

16. Karpissová, E. (2009). ENVIRONMENTAL MANAGEMENT AND ITS INFLUENCE ON A COMPANY PERFORMANCE. New Economic Challenges, 420.

17. Kramoliš, J., Staňková, P., \& Richtr, M. (2015). The importance of design in business practices of Czech companies. E a M: Ekonomie a Management, 18(2), 151-164. doi:10.15240/ tul/001/2015-2-011

18. Krenar, P., \& Taraba, P. (2010). The holistic competence of multicultural team member in the Czech organizations. Knowledge Management and Innovation: A Business Competitive Edge Perspective, Vols 1-3.

19. Lloyd, C., \& Ramsay, T. (2015). Macroeconomic prosperity and social inclusion: From longrun history to the shock of May 2014. Journal of Australian Political Economy, (74), 38-56 
20. Melewar, T. C., Dennis, C., \& Kent, A. (2014). Global design, marketing and branding: introduction to the special issue. Journal of Business Research, 67(11), 2241-2242. doi:10.1016/ j.jbusres.2014.06.011

21. Mozota, B. (2002). Design and competitive edge: A model for design management excellence in European SMEs. Academic Review, 2(1), 88-103.

22. Mozota, B. (2003). Design management: using design to build brand value and corporate innovation. Skyhorse Publishing Inc.

23. Mozota, B. (2006). The four powers of design: A value model in design management. Design Management Review, 17(2), 44-53. doi:10.1111/j.1948-7169.2006.tb00038.x

24. Oakley, M. (1990). Design management: A handbook of issues and methods. Oxford, UK: Blackwell Reference.

25. PROSPERITY INDEX. (2015). Retrieved June 10, 2015, from http://www.li.com/ programmes/prosperity-index

26. Roy, R., \& Potter, S. (1993). The commercial impacts of investment in design. Design studies, 14(2), 171-193.

27. Richtr, M. (2012). Design to prosperity. Unpublished manuscript.

28. Rundh, B. (2009). Packaging design: creating competitive advantage with product packaging. British Food Journal, 111(9), 988-1002. doi:10.1108/00070700910992880

29. Smith, L. M., Case, J. L., Smith, H. M., Harwell, L. C., \& Summers, J. K. (2013). Relating ecosystem services to domains of human well-being: Foundation for a US index. Ecological Indicators, 28, 79-90. doi:10.1016/j.ecolind.2012.02.032

30. Verganti, R. (2009). Design driven innovation. Harvard Business School Press, Boston.

31. Vesterstrøm, J., \& Thomsen, R. (2004). A comparative study of differential evolution, particle swarm optimization, and evolutionary algorithms on numerical benchmark problems. In Evolutionary Computation, 2004. CEC2004. Congress on (Vol. 2, pp. 1980-1987). IEEE.

32. Wells, L. E., Farley, H., \& Armstrong, G. A. (2007). The importance of packaging design for own-label food brands. International Journal of Retail \& Distribution Management, 35(9), 677 690. doi:10.1108/09590550710773237

33. What was not an effect of economic prosperity? (2015). Retrieved June 14, 2015, from http://www.answers.com/Q/What_was_not_an_effect_of_economic_prosperity

\section{Contact information}

Mgr. Jan Kramolis, Ph.D.

Tomas Bata University in Zlín

Faculty of Management and Economics

Department of Economics

E-mail:kramolis@fame.utb.cz. 